Supporting Information

\title{
Tumor-Specific Activatable Nanocarriers with Gas-Generation and Signal Amplification Capabilities for Tumor Theranostics
}

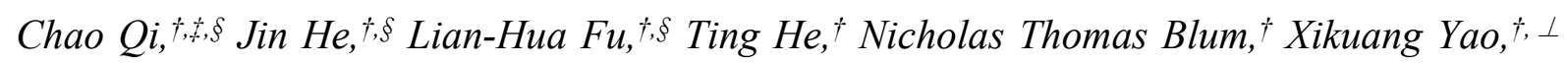
Jing Lin, ${ }^{\dagger}$ and Peng Huang*, +

'Marshall Laboratory of Biomedical Engineering, International Cancer Center, Laboratory of Evolutionary Theranostics (LET), School of Biomedical Engineering, Health Science Center, Shenzhen University, Shenzhen 518060, China.

Present address: Key Laboratory of Biorheological Science and Technology, Ministry of Education, College of Bioengineering, Chongqing University, Chongqing 400044, China.

$\perp$ Present address: Institute of Advanced Materials (IAM), Nanjing Tech University (NanjingTech), Nanjing 211800, China.

E-mail: peng.huang@szu.edu.cn

$\S$ These authors contribute equally. 

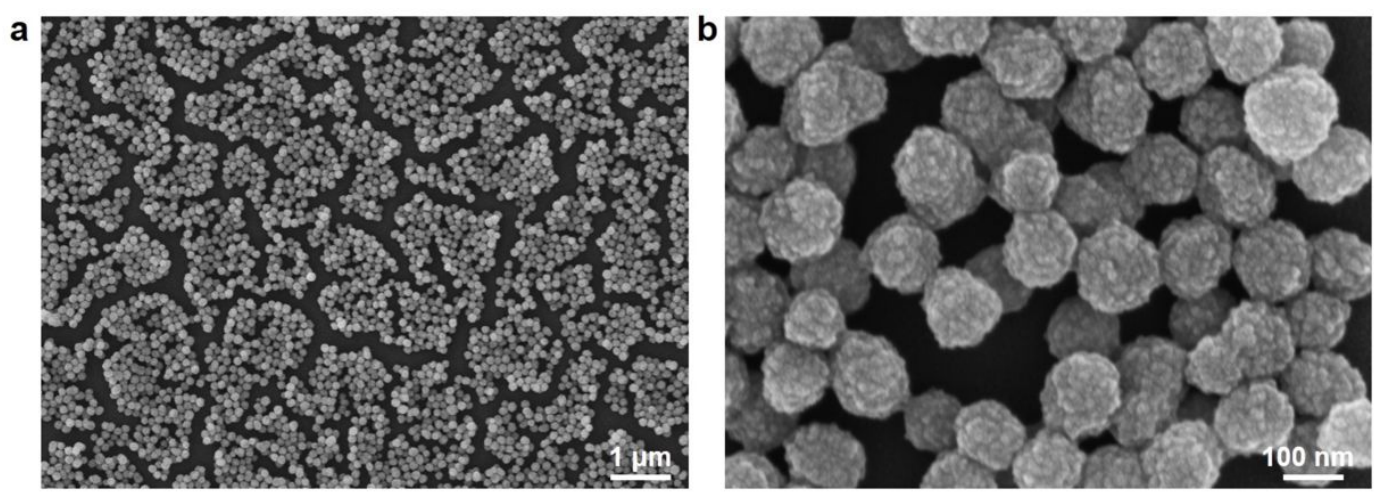

Figure S1. Representative scanning electron microscopy (SEM) images of BMC NPs at (a) low and (b) high magnification.

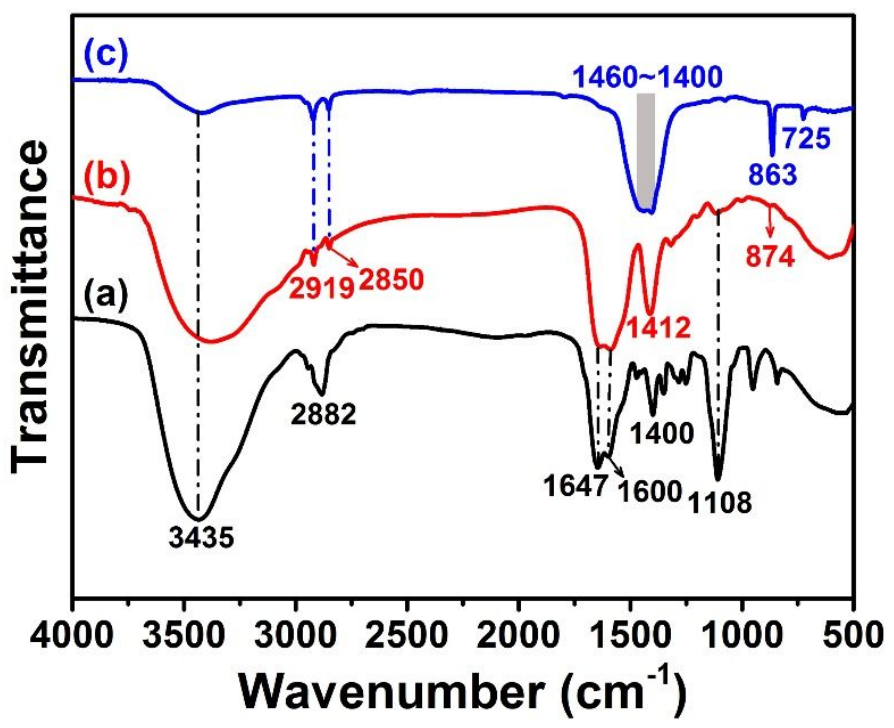

Figure S2. FTIR spectra of (a) PEG- $b$-PAsp, (b) BMC NPs and (c) pure $\mathrm{MnCO}_{3}$ prepared in the absence of PEG- $b$-PAsp. The broad absorption band at $\sim 3400 \mathrm{~cm}^{-1}$ is assigned to the absorbed water. The absorption peaks at $\sim 2919,2882$ and $2850 \mathrm{~cm}^{-1}$ are assigned to $-\mathrm{CH}_{2}$ and $-\mathrm{CH}_{3}$ stretching vibrations. The broad absorption band in the range of $1460-1400 \mathrm{~cm}^{-1}$ is the $v_{3}$ absorption of $\mathrm{CO}_{3}{ }^{2-}$, while the strong absorption band at $863 \mathrm{~cm}^{-1}$ and the relatively weak absorption band at $725 \mathrm{~cm}^{-1}$ are assigned to the $v_{2}$ out-plane bending and $v_{4}$ in-plane bending of $\mathrm{CO}_{3}{ }^{2-}$, respectively. The absorption amide peaks are located at $1647 \mathrm{~cm}^{-1}\left(v_{\mathrm{C}=0}\right)$, $1600 \mathrm{~cm}^{-1}\left(\delta_{\mathrm{N}-\mathrm{H}}\right)$, and 1400 and $1108 \mathrm{~cm}^{-1}\left(v_{\mathrm{C}-\mathrm{N}}\right)$. 




Figure S3. TG analysis of BMC NPs. The residual BMC (manganese oxide) was $30.7 \%$, thus the $\mathrm{MnCO}_{3}$ content in BMC NPs was calculated as $49.7 \%$. This result is consistent with the ICP-AES analysis, where the mass fraction of Mn in BMC NPs was $24.6 \%$, thus the content of $\mathrm{MnCO}_{3}$ in $\mathrm{BMC}$ was calculated as $51.4 \%$.

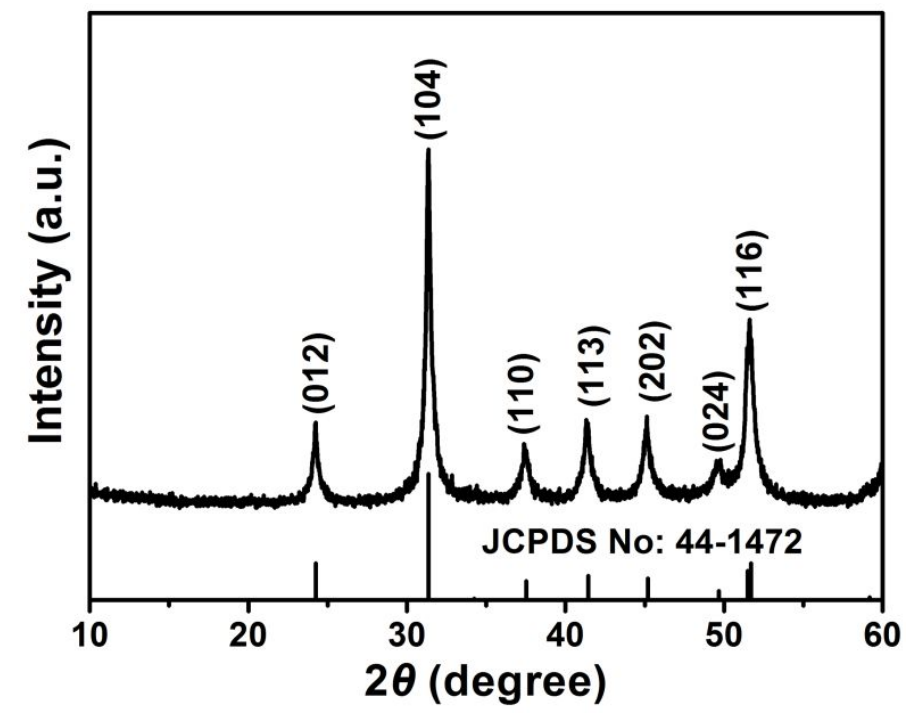

Figure S4. The XRD pattern of pure $\mathrm{MnCO}_{3}$ prepared in the absence of PEG- $b$-PAsp. 


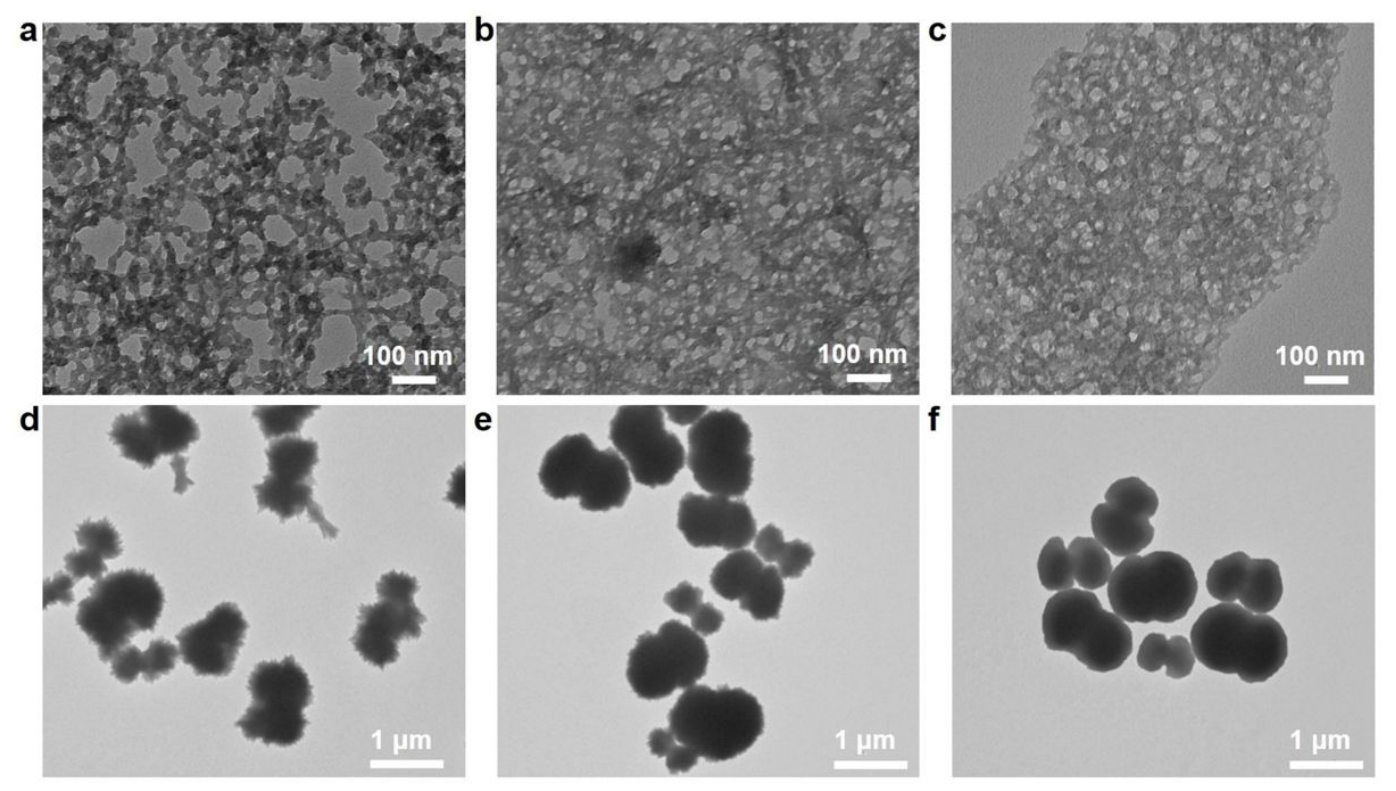

Figure S5. TEM images of BMC prepared with different $\mathrm{Na}_{2} \mathrm{CO}_{3}$ concentrations: (a) $5 \mathrm{mM}$, (b) $10 \mathrm{mM}$, (c) $15 \mathrm{mM}$, (d) $25 \mathrm{mM}$, (e) $35 \mathrm{mM}$, (f) $50 \mathrm{mM}$.
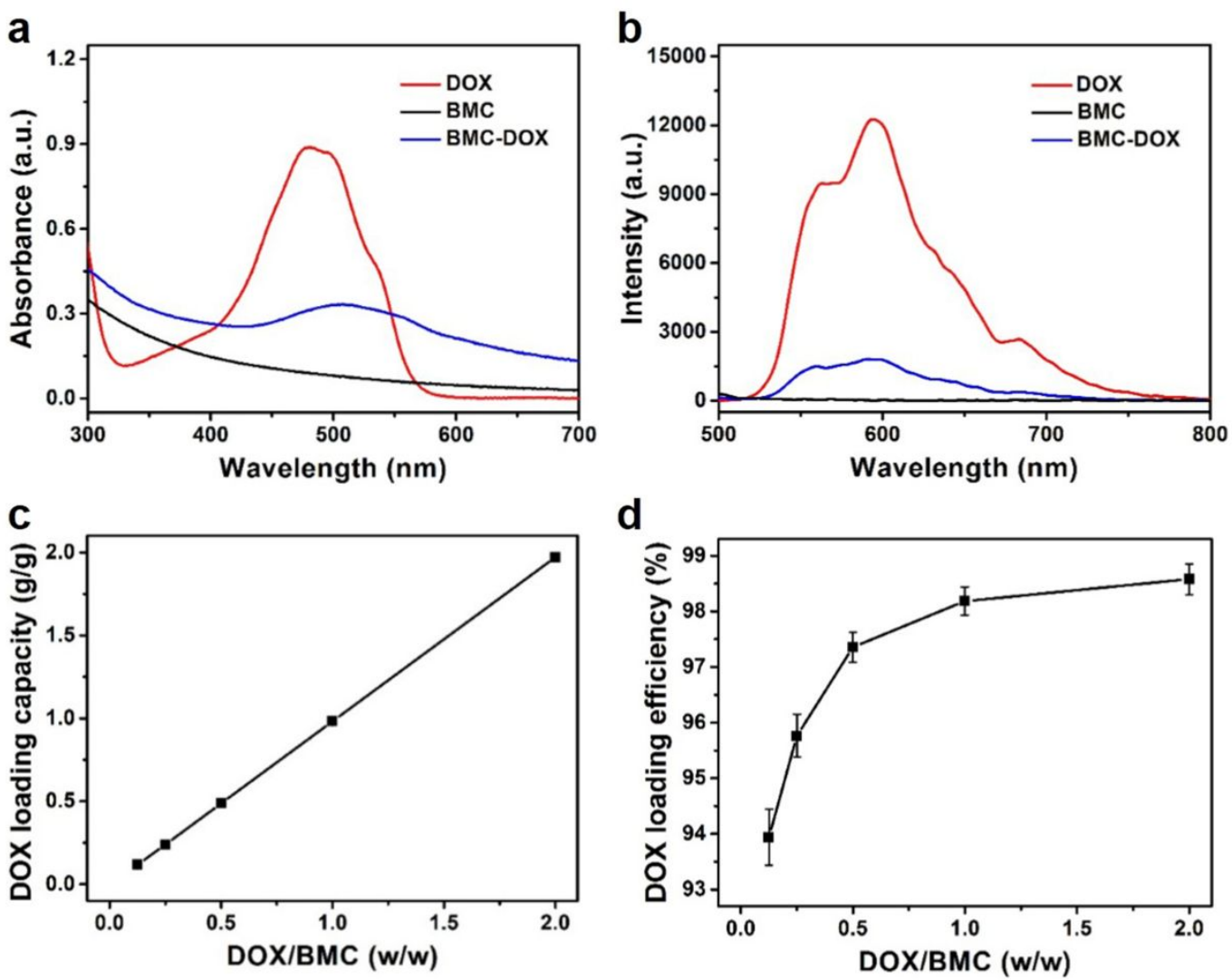

Figure S6. (a) UV-Vis absorption and (b) fluorescence spectra of DOX, BMC and BMC-DOX solutions. (c) DOX loading capacity and (d) loading efficiency of BMC NPs as a function of the initial DOX/BMC feed ratio. 


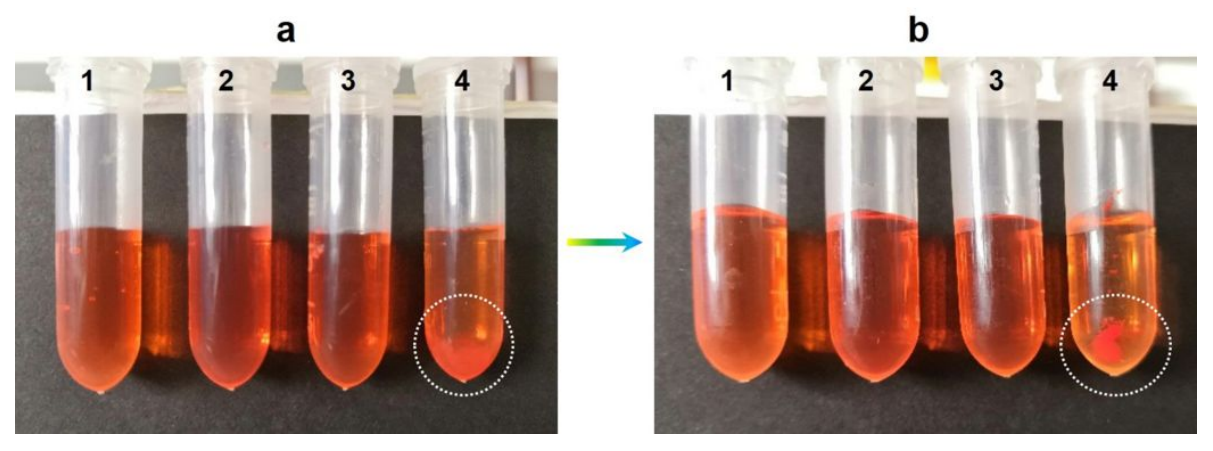

Figure S7. Photographs of the different solutions (a) before and (b) after centrifugation. (1): DOX, (2): DOX + PEG-b-PAsp, (3): DOX $+\mathrm{Mn}^{2+}$ ions, (4): DOX + PEG- $b$-PAsp $+\mathrm{Mn}^{2+}$ ions. $[\mathrm{DOX}]=0.2 \mathrm{mg} \mathrm{mL}{ }^{-1}$, [PEG- $b$-PAsp $]=1.6 \mathrm{mg} \mathrm{mL}{ }^{-1},\left[\mathrm{Mn}^{2+}\right]=10 \mathrm{mM}$. The white circles indicate the precipitation.

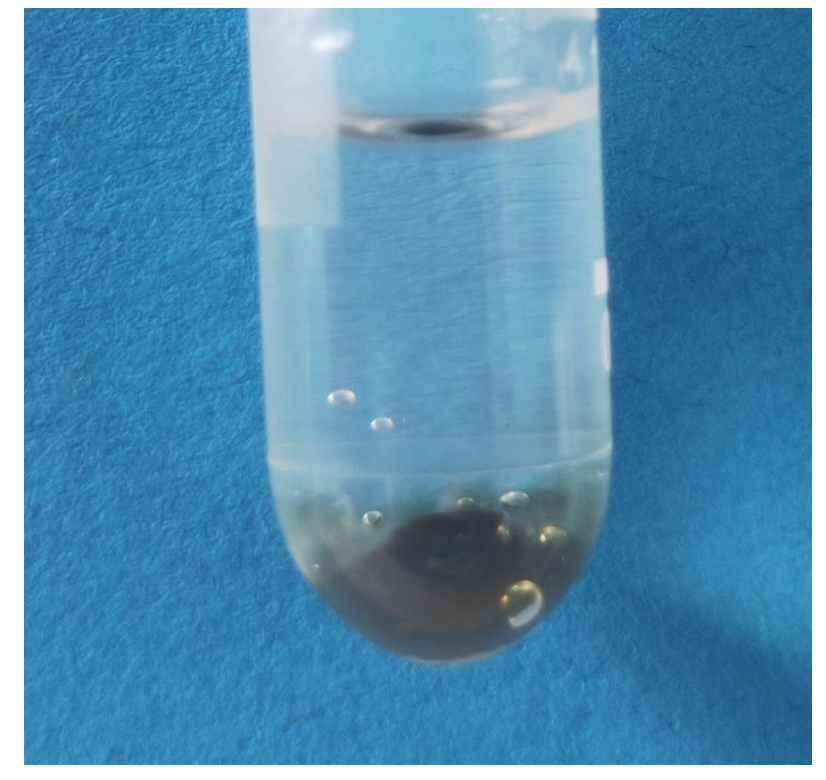

Figure S8. Photograph of the $\mathrm{pH}$-activated $\mathrm{CO}_{2}$ gas generation process. 

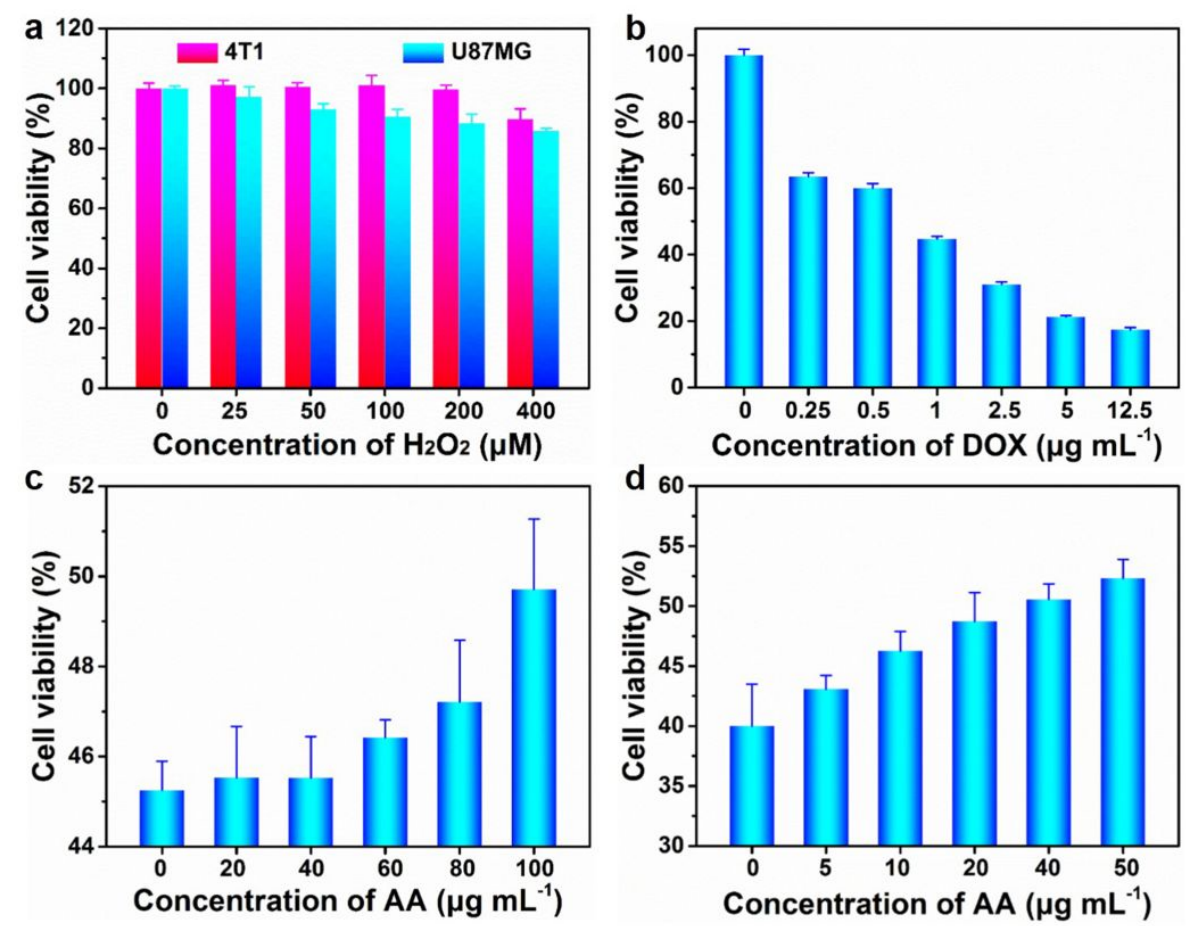

Figure S9. (a) 4T1 and U87MG cell viability after incubation with different concentrations of $\mathrm{H}_{2} \mathrm{O}_{2}$ for $24 \mathrm{~h}$. (b) $4 \mathrm{~T} 1$ cell viability after incubation with different concentrations of DOX for 24 h. (c) $4 \mathrm{~T} 1$ cell viability after incubation with $\mathrm{BMC}\left(50 \mu \mathrm{g} \mathrm{mL} \mathrm{m}^{-1}\right), \mathrm{H}_{2} \mathrm{O}_{2}(400 \mu \mathrm{M})$ and different concentrations of $L$-ascorbic acid (AA). (d) U87MG cell viability after incubation with BMC $\left(400 \mu \mathrm{g} \mathrm{mL} \mathrm{mL}^{-1}\right), \mathrm{H}_{2} \mathrm{O}_{2}(400 \mu \mathrm{M})$ and different concentrations of AA. The data represent the means \pm standard deviation (s.d.). 


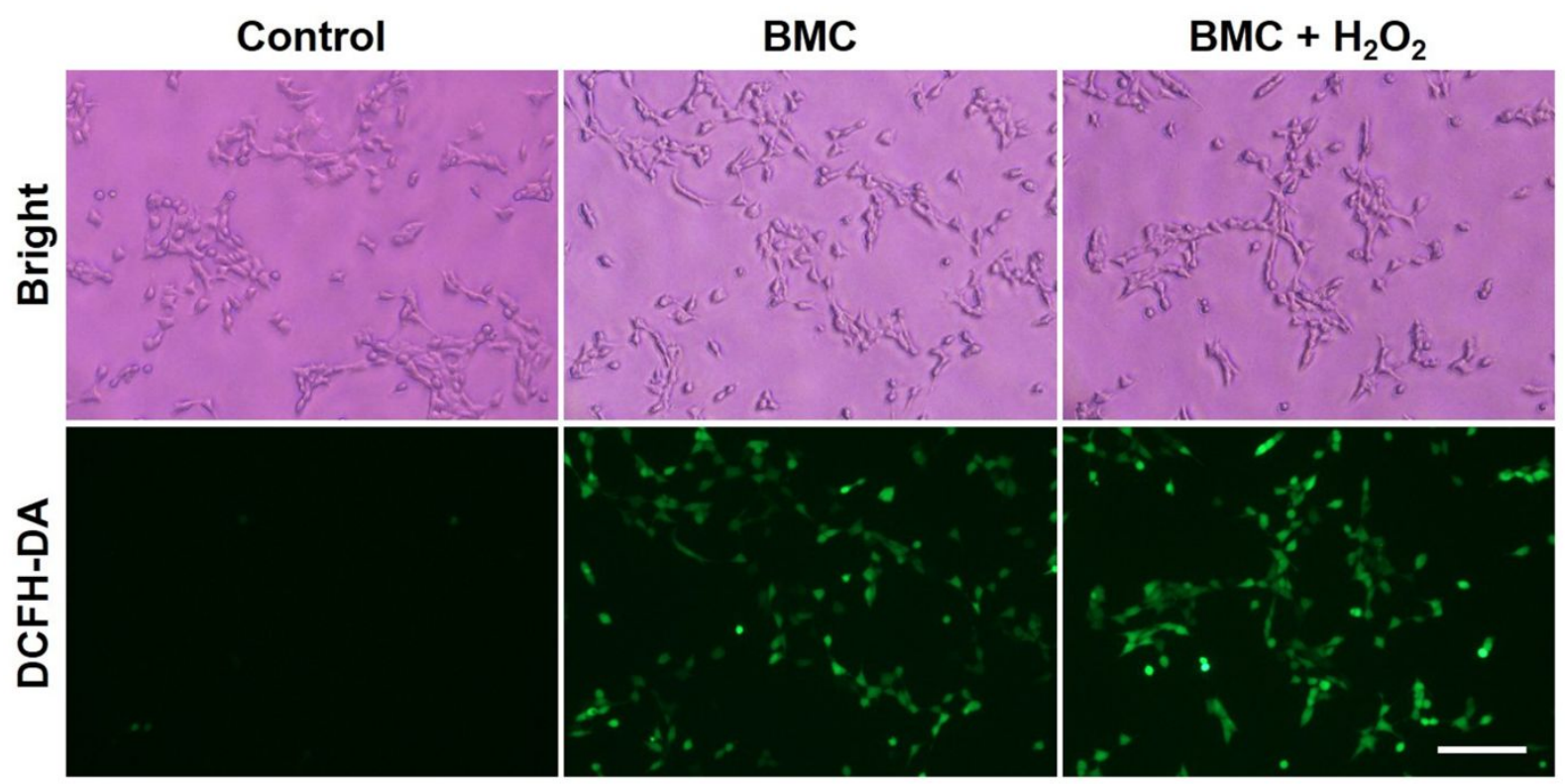

Figure S10. Microscopy images of 4T1 cells after incubation with fresh medium (control group), $\mathrm{BMC}$, and $\mathrm{BMC}+\mathrm{H}_{2} \mathrm{O}_{2}$ for $2 \mathrm{~h}$, and stained with ROS fluorescene probe DCFH-DA. Scale bar: $100 \mu \mathrm{m}$. 




Figure S11. Confocal laser scanning microscopic images of 4T1 cells after co-incubation with BMC-DOX for different times. Scale bar: $50 \mu \mathrm{m}$. Blue fluorescence: DAPI (stained the cell nucleus); red fluorescence: DOX. 


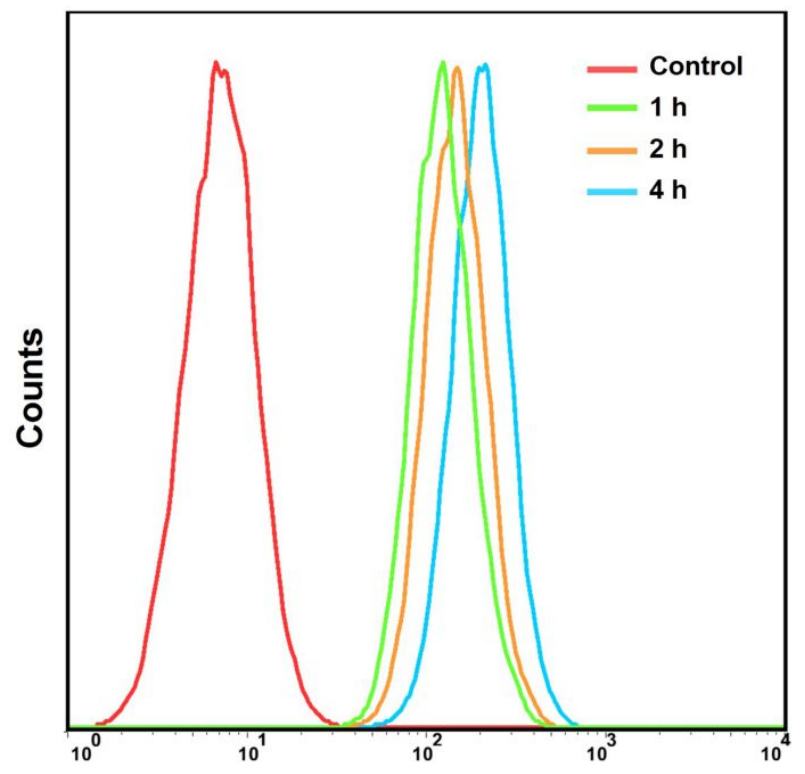

Figure S12. Flow cytometry analysis of 4T1 cells after co-incubation with BMC-DOX for different time.

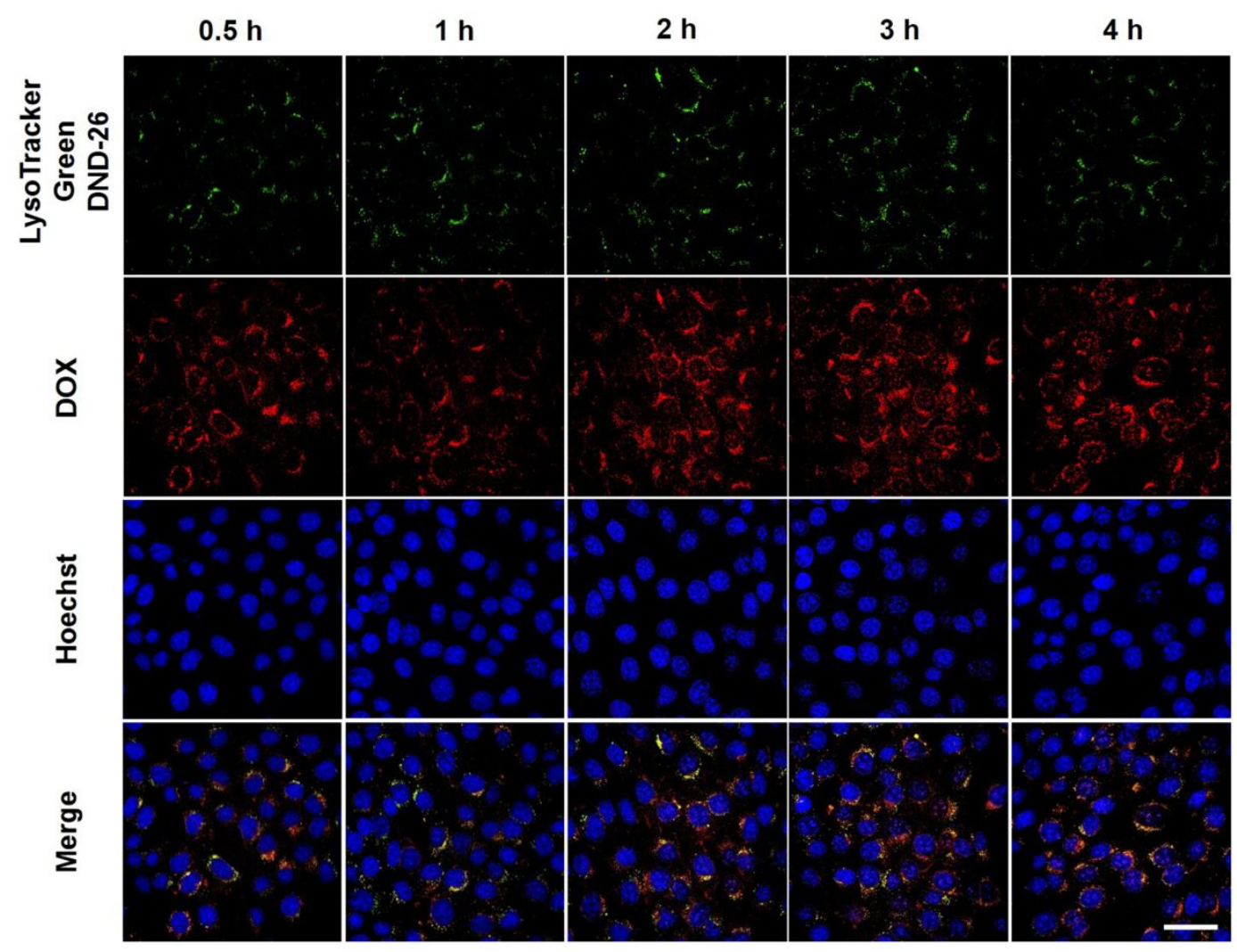

Figure S13. Fluorescence images of $4 \mathrm{~T} 1$ cells after co-incubation with BMC-DOX for different times. Scale bar: $50 \mu \mathrm{m}$. Green fluorescence: LysoTracker Green DND-26 (stained the lysosome); Red fluorescence: DOX; Blue fluorescence: Hoechst (stained the cell nucleus). 


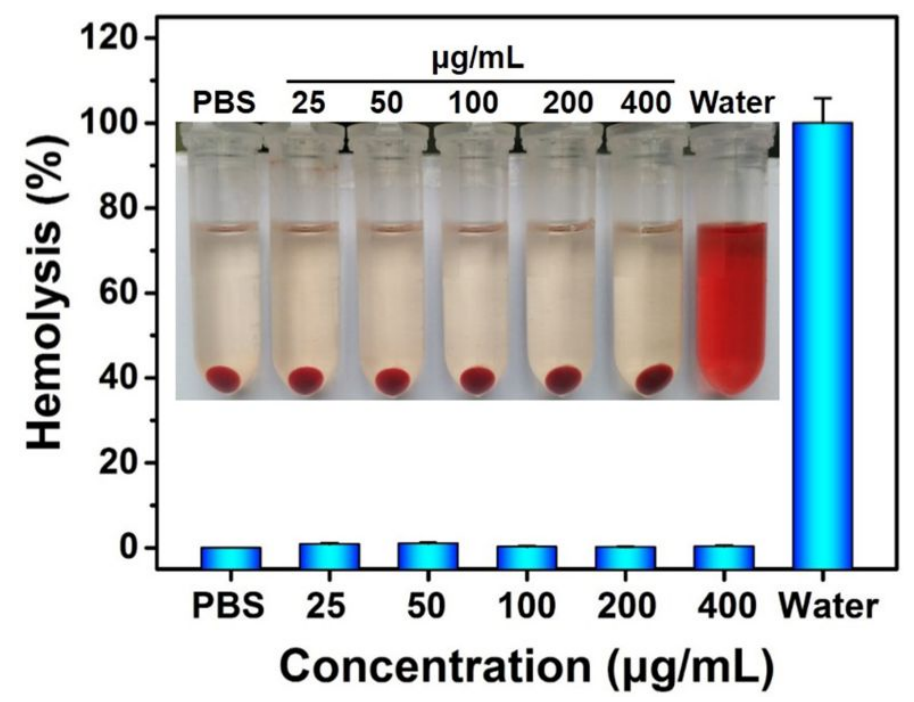

Figure S14. Hemolysis analysis of the BMC suspension at various concentrations. The mixtures were left to stand for $3 \mathrm{~h}$ and then centrifuged before visually assessing the hemoglobin level in the supernatant (inset photo). The hemolysis rates of BMC at different concentrations $(0-400 \mu \mathrm{g} \mathrm{mL}-1)$ were $<1 \%$. The data represent the means \pm s.d., $\mathrm{n}=3$.



Figure S15. The biodistribution of Mn element after intravenous injection of BMC NPs for 8 $\mathrm{h}$ and $24 \mathrm{~h}$. The data represent the means \pm s.d., $\mathrm{n}=3$. 
a

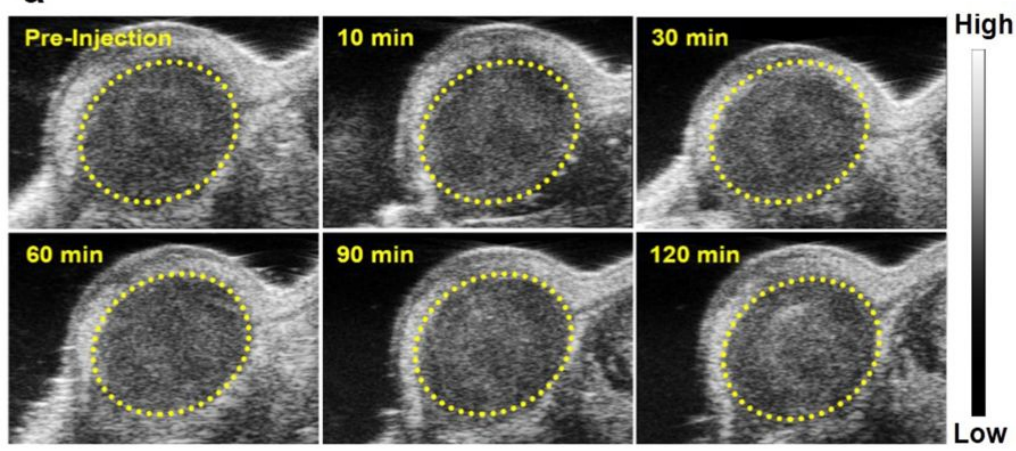

b

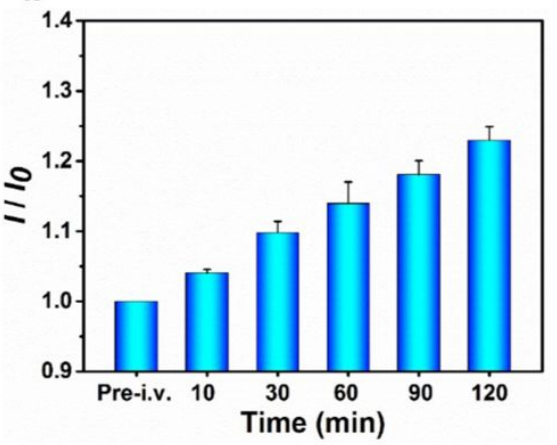

Figure S16. (a) In vivo USI of the $4 \mathrm{~T} 1$ tumor pre- and post- intravenous BMC injection at various time points. (b) The quantified USI intensity of 4T1 tumors treated with BMC by intravenous injection as a function of time ( $I_{0}$ is the ultrasound intensity of preinjection). The data represent the means \pm s.d., $n=3$.

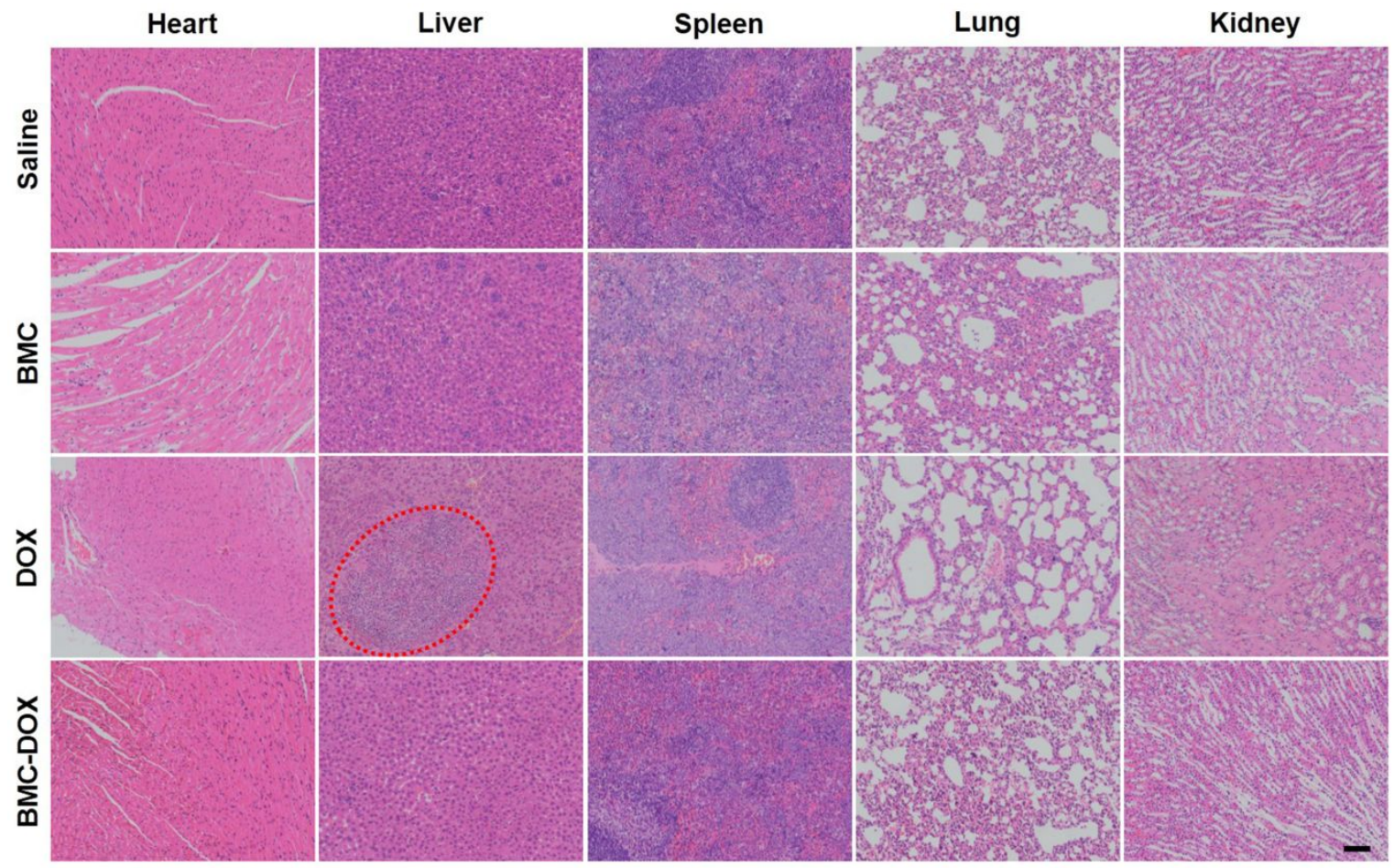

Figure S17. H\&E images of the indicated major organs removed from mice after different treatments. The major organs of the mice in the DOX group were isolated on day 8 due to the systemic toxicity of free DOX; the red circle indicate the damaged area in liver. The mice in the other groups were sacrificed on day 14 after treatment, and the major organs were collected for H\&E staining. Scale bar: $100 \mu \mathrm{m} .[\mathrm{BMC}]=10 \mathrm{mg} \mathrm{kg}^{-1}$, [DOX] $=5 \mathrm{mg} \mathrm{kg}^{-1}$. 

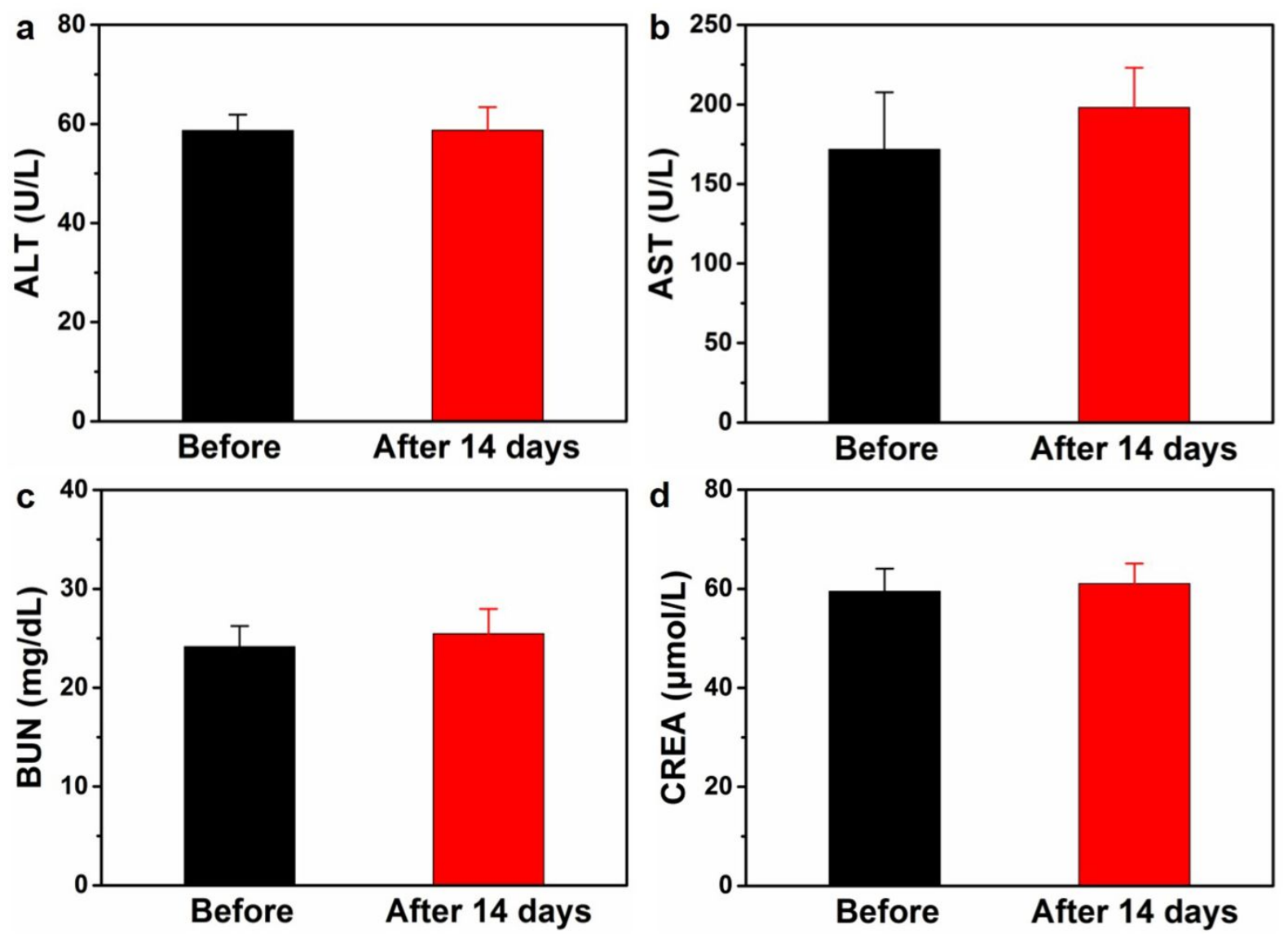

Figure S18. The standard biochemical index of the mice before and after 14 days of intravenous injection of BMC-DOX. (a) ALT and (b) AST levels reflect liver function. (c) BUN and (d) CREA levels reflect renal function. The data represent the means \pm s.d., $\mathrm{n}=5$. 